OPEN ACCESS

Edited by: Annette Gaertner, Evotec (Germany), Germany

Reviewed by: Eckart Förster, Ruhr University Bochum, Germany Gonzalo Alvarez-Bolado, Heidelberg University, Germany

*Correspondence:

Michael Frotscher michael.frotscher@zmnh.unihamburg.de

Received: 10 February 2017 Accepted: 05 May 2017 Published: 23 May 2017

Citation: Frotscher M, Zhao S, Wang S and Chai X (2017) Reelin Signaling Inactivates Cofilin to Stabilize the Cytoskeleton of Migrating Cortical Neurons.

Front. Cell. Neurosci. 11:148. doi: 10.3389/fncel.2017.00148

\section{Reelin Signaling Inactivates Cofilin to Stabilize the Cytoskeleton of Migrating Cortical Neurons}

\author{
Michael Frotscher ${ }^{1 *}$, Shanting Zhao ${ }^{2}$, Shaobo Wang ${ }^{1}$ and Xuejun Chai ${ }^{1}$ \\ ${ }^{1}$ Center for Molecular Neurobiology Hamburg (ZMNH), Institute for Structural Neurobiology, University Medical Center \\ Hamburg-Eppendorf, Hamburg, Germany, ${ }^{2}$ College of Veterinary Medicine, Northwest A\&F University, Yangling, China
}

Neurons are highly polarized cells. They give rise to several dendrites but only one axon. In addition, many neurons show a preferred orientation. For example, pyramidal neurons of the cerebral cortex extend their apical dendrites toward the cortical surface while their axons run in opposite direction toward the white matter. This characteristic orientation reflects the migratory trajectory of a pyramidal cell during cortical development: the leading process (the future apical dendrite) extends toward the marginal zone (MZ) and the trailing process (the future axon) toward the intermediate zone (IZ) while the cells migrate radially to reach their destination in the cortical plate (CP). In this review article, we summarize the function of Reelin, an extracellular matrix protein synthesized by Cajal-Retzius cells in the $\mathrm{MZ}$, in the development of the characteristic orientation of the leading processes running perpendicular to the cortical surface. Reelin promotes migration toward the cortical surface since late-generated cortical neurons in the reeler mutant are unable to reach upper cortical layers. Likewise, Reelin is important for the orientation and maintenance of the leading processes of migrating neurons since they are misoriented in the developing reeler cortex, as are the apical dendrites of pyramidal cells in the mature mutant. Reelin-induced phosphorylation of cofilin, an actin-associated protein, is crucial since pyramidal neurons transfected by in utero electroporation (IUE) with a non-phosphorylatable form of cofilin (cofilin ${ }^{\mathrm{S} 3 \mathrm{~A}}$ ) show severe migration defects reminiscent of those in the reeler mutant. Remarkably, migration of neurons in the cortex of reeler mice was partially rescued by transfecting them with LIM kinase 1 (LIMK1), the kinase that induces phosphorylation of cofilin at serine3, or with a pseudophosphorylated cofilin mutant (cofilin ${ }^{\mathrm{S} 3}$ ). Together these results indicate that Reelininduced phosphorylation of cofilin is an important component in the orientation and directed migration of cortical neurons and in their correct lamination.

Keywords: neuronal orientation, cortical pyramidal neuron, neuronal migration, leading process, trailing process, Reelin, cofilin, in utero electroporation

\section{INTRODUCTION}

The student of the mammalian cerebral cortex is impressed by two phenomena pointing to a well-ordered, non-random structural organization. First, there is the arrangement of cortical neurons in layers as seen in Nissl-stained sections or in sections immunostained using layer specific markers. Second, there is an almost uniform vertical orientation of the vast majority of cortical 
neurons. This is nicely seen when cortical neurons are impregnated using the Golgi method which stains the cells with their axonal and dendritic processes (Golgi, 1873). The vertical orientation mainly comes about by the thick, long apical dendrites originating from the cell bodies and running toward the pial surface where they branch, forming apical tufts. From the opposite poles of the cell bodies the axons originate, which run toward the white matter. Thus, this vertical orientation of virtually all cortical pyramidal neurons nicely illustrates the characteristic bipolarity of nerve cells having one efferent process, the axon, and many dendrites being the receptive processes of the cell conveying incoming signals toward the cell body. In a cortical pyramidal cell the two processes, the apical dendrite and the axon, run in fact in opposite directions as noticed early on by investigators applying the Golgi method (e.g., Ramón y Cajal, 1911).

From a cell biological point of view numerous questions arise after this short description of cortical organization. Numerous researchers have dealt intensely with these questions during the last decades. In a landmark article, Berry and Rogers (1965) described for the first time that there is an "insideout" lamination with early-generated neurons establishing the deep layers and late-generated neurons the superficial layers of the cerebral cortex. In a way, this finding came as a surprise because the late-generated neurons did not simply push away the early-generated ones, which would have resulted in an opposite layering. Late-generated neurons rather have to tackle the task of bypassing a densely packed layer of earlier generated cells. This also includes that late-generated neurons trespassing earlygenerated deep layer cells have to migrate for much longer distances to reach their destination. How is this achieved? How do late-generated neurons find their way to the surface of the cortex?

Developmental studies in various species and more recently real-time microscopy of migrating neurons in the cortex have contributed much to our understanding of the journey of late-generated neurons through the layers of their predecessors (Nadarajah et al., 2001; Nadarajah and Parnavelas, 2002). It has become clear that a migrating neuron moves in the direction of its thick leading process and that this is associated with a translocation of the nucleus in this direction. With the leading process becoming the main apical dendrite, the vertical orientation of pyramidal cells in the mature cortex represents a frozen picture of its development, particularly of the directionality of the migratory process. What are the signals that control this directionality? Radial glial cell processes span the distance between the ventricle and the cortical surface, serving as a guiding scaffold for migrating neurons (Rakic, 1972). What are the signals controlling their orientation? What are the signals that anchor the leading processes of pyramidal neurons to the pial surface and how is this particular vertical orientation of apical dendrites maintained throughout life?

Much has been learned in the past from mouse mutants. A perfect example is the reeler mutant described as early as in 1951 (Falconer, 1951). In this mutant, the normal inside-out lamination of the cerebral cortex is inverted and the majority of

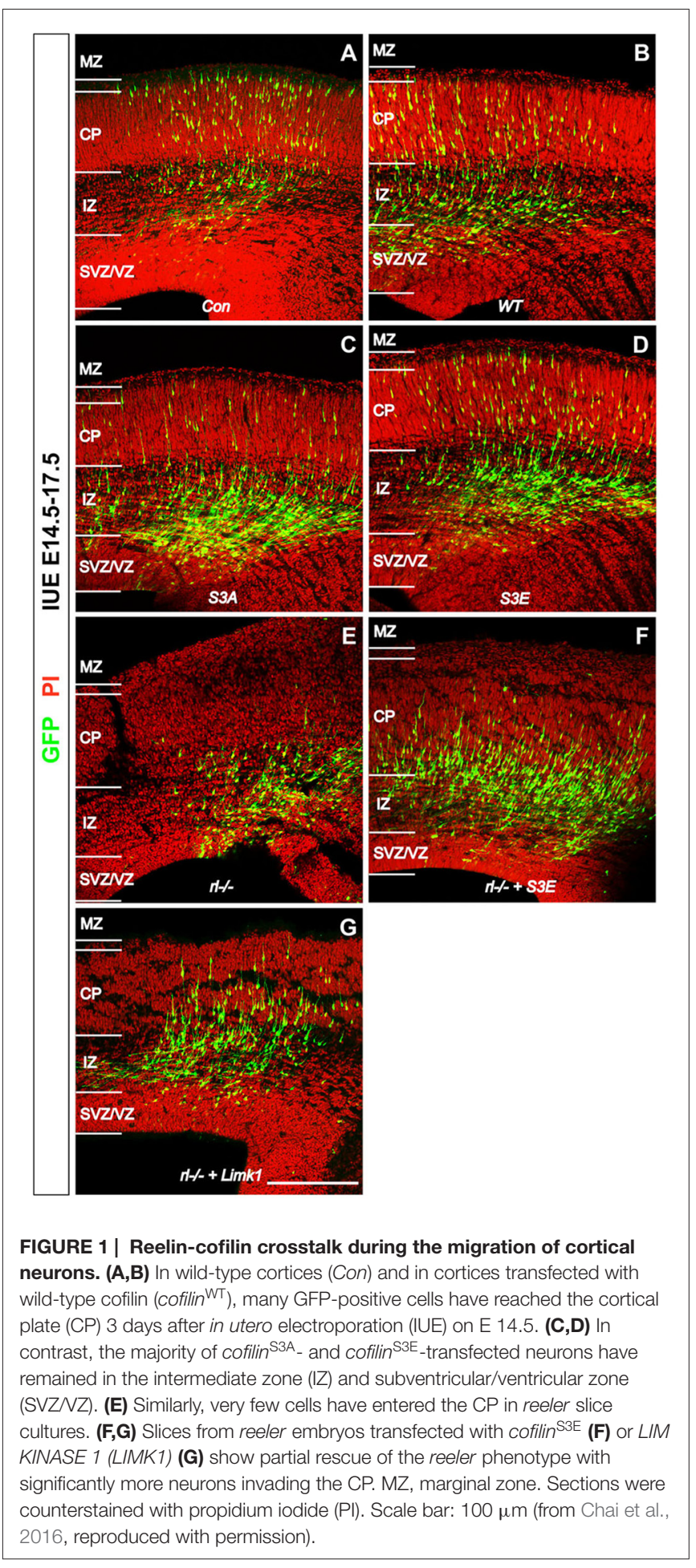

cortical pyramidal cells are misoriented, pointing to an important defect in molecular pathways but at the same time also to an interdependence of process orientation and cortical layer formation. With the discovery of Reelin, the molecule deficient in the reeler mutant, research in this area has exploded and our understanding of layer formation in the cortex and of the different players involved has significantly improved. 

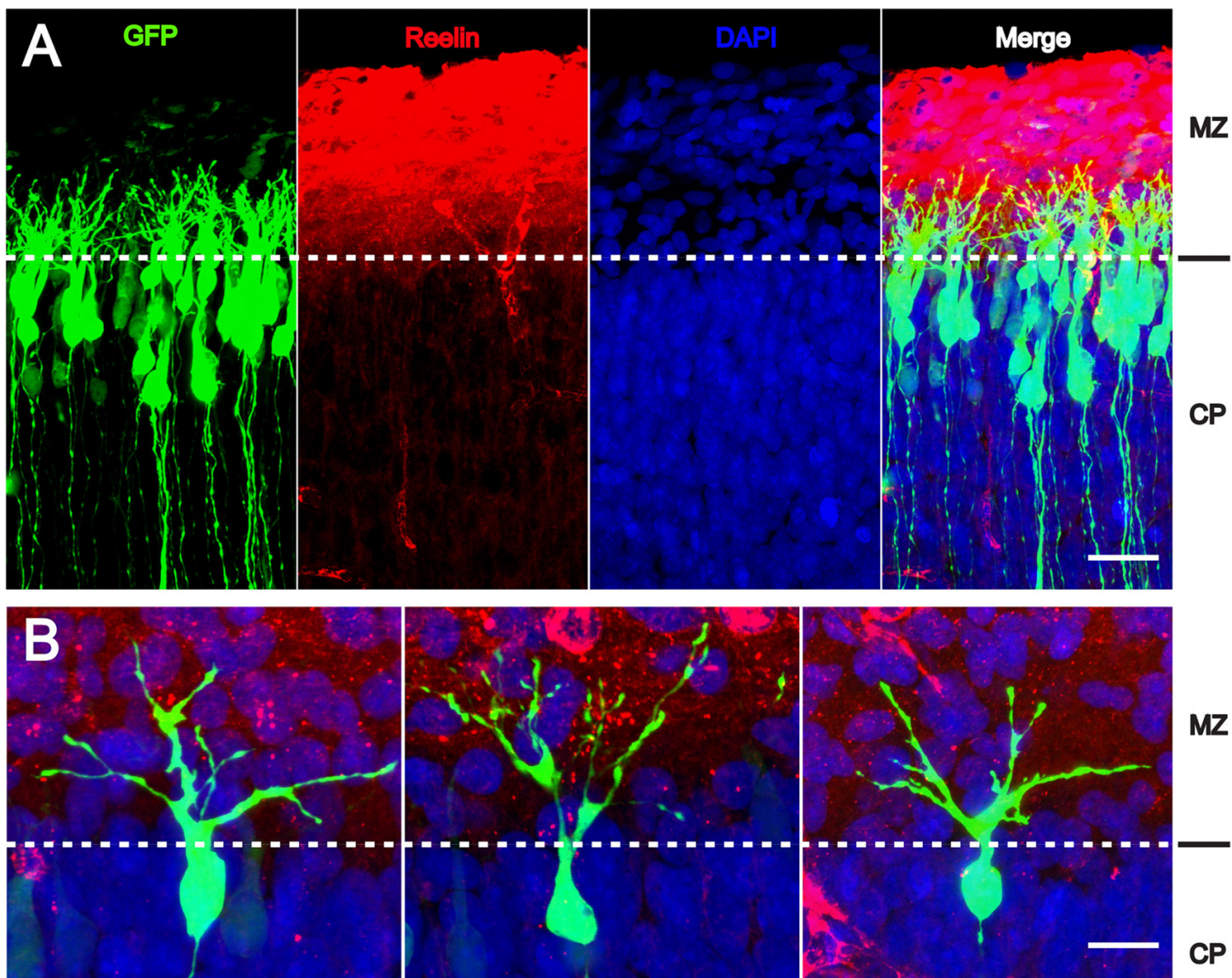

FIGURE 2 | Reelin-induced branching of the leading processes. (A,B) The leading processes of migrating neurons start to branch as soon as they reach the MZ containing Reelin. Transfection of wild-type embryos with CAG-GFP on E 14.5; fixation on E 17.5. CP, cortical plate. Scale bars: $40 \mu \mathrm{m}$ (A); $15 \mu \mathrm{m}$ (B) (modified from Chai et al., 2015, with permission).

\section{REELIN RECEPTORS AND THE REELIN SIGNALING CASCADE}

The name Reelin is attributed to reeler, a natural mouse mutant described long before the Reelin gene was found (Falconer, 1951). As suggested by its name, the reeler mouse shows an impressive phenotype dominated by severe ataxia. Reelin is a large $400 \mathrm{kDa}$ glycoprotein of the extracellular matrix which is synthesized and secreted by Cajal-Retzius cells (D'Arcangelo et al., 1995; Ogawa et al., 1995), an early class of cortical neurons that were described in detail in Golgi preparations by Santiago Rámon y Cajal and Gustaf Retzius at the turn of last century. Of note, Cajal-Retzius cells populate the marginal zone (MZ) of the developing cortex, future layer I. Thus, full-length Reelin and its fragments are highly concentrated at the top of the developing cortex, suggesting that this characteristic topographical distribution is important for the control of migratory processes underneath, i.e., for the migration of cortical neurons from the ventricle to the cortical surface. Is Reelin in the MZ an attractive molecule for newborn neurons generated near the ventricle? Nichols and Olson (2010) have shown that Reelin induces orientation and alignment of earlygenerated layer Vl neurons and preplate splitting. Moreover, a role for Reelin in the directed migration of cortical neurons is consistent with the observation that in reeler late-generated neurons are unable to migrate through deep, early-generated cell layers, likely because their attractive force is missing in the mutant (Zhao et al., 2004). However, in reeler, but not in wild type, layer I of the cortex, the former MZ, is densely populated, suggesting an opposite effect, a stop signal function for Reelin (Zhao and Frotscher, 2010). Could it be that full-length Reelin in the MZ has different functions than the various Reelin fragments, diffusing to deeper cortical layers? Reelin is composed of an N-terminal F-spondin-like domain, eight repeats, and a short and highly basic C-terminal region. Reelin is cleaved at two sites approximately located between repeats 2 and 3 and between repeats 6 and 7, resulting in a total of five different fragments $(370 \mathrm{kDa}, 270 \mathrm{kDa}, 190 \mathrm{kDa}, 180 \mathrm{kDa}$ and $80 \mathrm{kDa}$ ) in addition to the full-length protein (Lambert de Rouvroit et al., 1999; Ignatova et al., 2004). Of note, inhibition of processing alters cortical lamination (unpublished observations). 

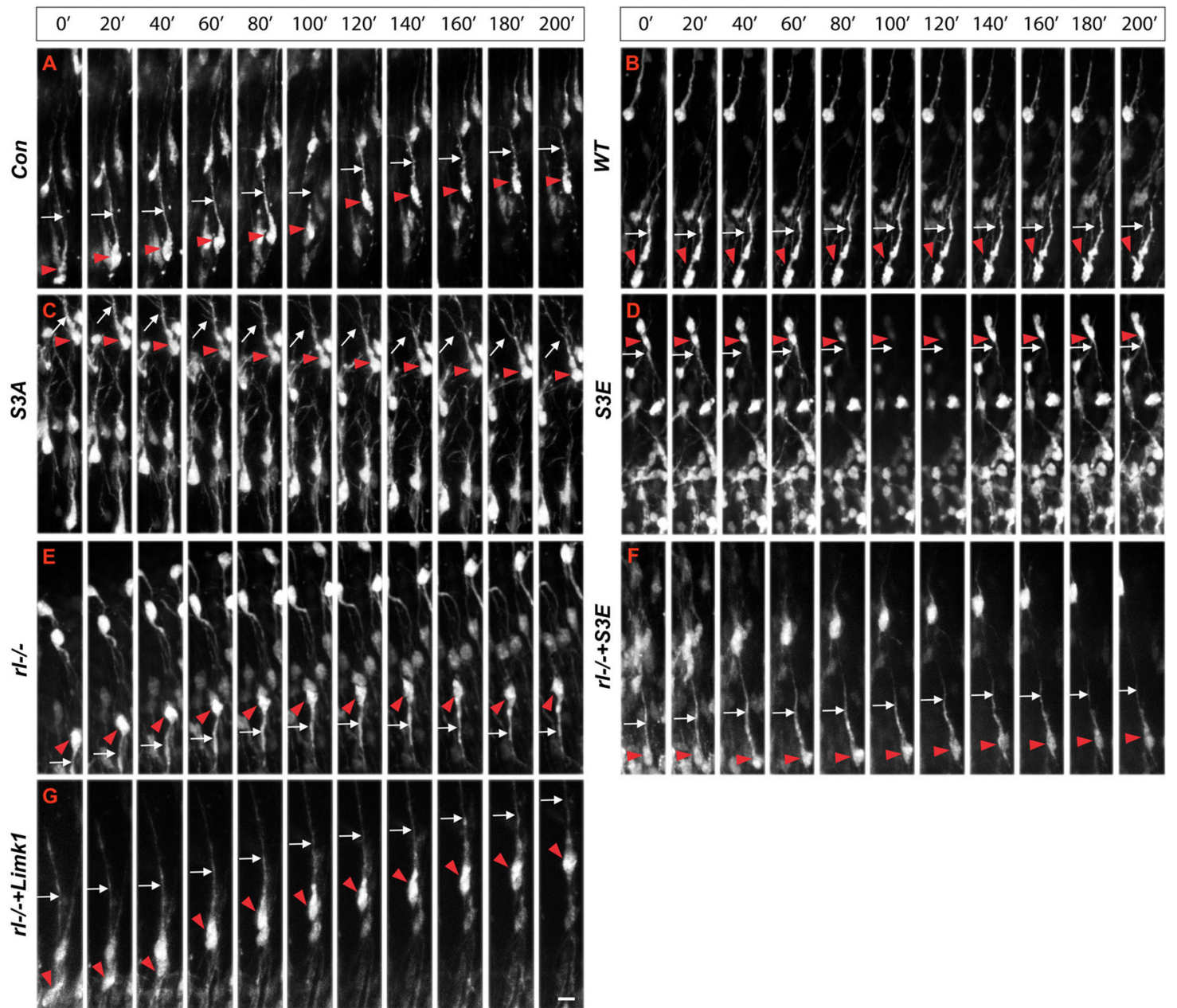

FIGURE 3 | Real-time microscopy of migrating neurons transfected with the different constructs. (A-G) Following in IUE on E 14.5, slice cultures were prepared on E 17.5 and single neurons were monitored over a period of $200 \mathrm{~min}$. Red arrowheads mark the cell bodies and white arrows the leading processes of migrating neurons. The $\mathrm{MZ}$ is at the top of the figures, the $\mathrm{VZ}$ at the bottom. Note aberrant leading processes pointing toward the $\mathrm{VZ}$ in reeler neurons $\left(r{ }^{-/-}\right)$and neurons transfected with cofilin ${ }^{\mathrm{S} 3 \mathrm{E}}$. Neurons in reeler slices transfected with $L I M K 1$ or cofilin ${ }^{\mathrm{S} 3 \mathrm{E}}$ show a normal leading process oriented toward the MZ. Scale bar: $15 \mu \mathrm{m}$ (from Chai et al., 2016, reproduced with permission).

Or could it be that different Reelin receptors were involved? It came as a surprise that Reelin binds to lipoprotein receptors and that a double knockout mouse deficient in the two lipoprotein receptors, apolipoprotein $\mathrm{E}$ receptor 2 (ApoER2) and very low-density lipoprotein receptor (VLDLR), showed a reeler phenotype (D’Arcangelo et al., 1999; Hiesberger et al., 1999; Trommsdorff et al., 1999). Mutants deficient in only one of these receptors showed phenotypes that were milder and also different from each other (Hack et al., 2007). Thus, while in ApoER2 knockout mice late-generated neurons were unable to bypass early-generated cells like in the reeler mutant, mutants deficient in VLDLR displayed another feature of the reeler phenotype, the characteristic invasion of the MZ (Hack et al., 2007). Indeed, the two receptor types were found differently distributed in the cortex with the VLDLR receptor being mainly located in upper cortical layers (Hirota et al., 2014), suggesting that this receptor would be responsible for the stop signal function of Reelin (Hack et al., 2007). Besides these two lipoprotein receptors, cadherin-related neuronal receptors (CNRs; Senzaki et al., 1999) and alpha3betal integrins (Dulabon et al., 2000) were described to function as Reelin receptors. Binding of Reelin to ApoER2 and VLDLR was found to induce the phosphorylation of disabled 1 (Dab1; Howell et al., 1999; Benhayon et al., 2003), an adaptor protein binding to the intracellular domains of the lipoprotein receptors. Mutants deficient in Dab1 showed a reeler-like phenotype (Sheldon et al., 1997). The Reelin signaling cascade involves in addition src family kinases which phosphorylate Dab1, phosphatidylinositol 3-kinase (PI3K), and glycogen synthase kinase 3 beta (GSK3B), the latter kinase being known to phosphorylate Tau (Hiesberger et al., 1999). Hyperphosphorylation of 
Tau is a hallmark of Alzheimer's disease, suggesting an involvement of the Reelin signaling cascade in the pathology of this disorder but further work is needed to obtain a clearer picture.

\section{REELIN ACTS UPSTREAM OF COFILIN TO FACILITATE MIGRATION}

We previously found that Reelin induces phosphorylation (activation) of LIM kinase 1 (LIMK1), a kinase that in turn induces phosphorylation of cofilin (Chai et al., 2009). Cofilin is an actin-depolymerizing protein that is inactivated by its phosphorylation at serine3 (Arber et al., 1998; Yang et al., 1998). Since Reelin induces the phosphorylation of cofilin, one is tempted to conclude that Reelin counteracts cytoskeletal reorganization and in turn stabilizes the actin cytoskeleton in neuronal processes. In the present review article we will not discuss other molecules of the Reelin signaling cascade in detail but will focus on Reelin's role in the stabilization of the actin cytoskeleton as an important prerequisite for the stability of the leading process which is needed for nuclear translocation during migratory activity. The reader is referred to several other review articles dealing in more detail with the various aspects of Reelin function (Rakic and Caviness, 1995; Curran and D’Arcangelo, 1998; Frotscher, 1998, 2010; Jossin et al., 2003; Tissir and Goffinet, 2003; Förster et al., 2006a,b; Cooper, 2008, 2013; Zhao and Frotscher, 2010; Chai and Frotscher, 2016).

Some time ago Bellenchi et al. (2007) reported that conditional cofilin mutants showed migration defects reminiscent of the reeler phenotype. Chai et al. (2009) then demonstrated that the amounts of phosphorylated cofilin are significantly reduced in reeler and that application of recombinant Reelin to reeler tissue significantly increased the phosphorylation of cofilin, suggesting that Reelin-induced cofilin phosporylation is important for the normal lamination of the cerebral cortex. This hypothesis was recently confirmed by in utero electroporation (IUE) experiments (Chai et al., 2016). Transfection of newly born cortical neurons with a non-phosphorylatable form of cofilin ( cofilin $^{\mathrm{S} 3 \mathrm{~A}}$ ) revealed a significant migration defect of the transfected cells, which remained near their site of origin in the subventricular zone (SVZ)-very much reminiscent of the reeler phenotype. Neurons transfected with a pseudophosphorylated form (cofilin $^{\mathrm{S} 3 \mathrm{E}}$ ) also showed a migration defect. Remarkably, transfection of reeler embryos with LIMK1 seemingly forced the phosphorylation of cofilin in these animals and resulted in a partial rescue of the migration defect in reeler, as did transfection with pseudophosphorylated cofilin ${ }^{\mathrm{S} 3 \mathrm{E}}$. These results on GFP-expressing neurons were obtained by IUE on embryonic day (E) 14.5, sacrificing the embryos on E17.5 and counterstaining sections of the cortex for propidium iodide (PI; Figure 1). Remarkably, neurons transfected with the cofilin mutants, similarly to GFP transfected reeler neurons, often showed leading processes oriented toward the ventricle. Collectively, these results suggest that Reelininduced stabilization of the leading process, likely by the phosphorylation of cofilin, is an essential step in the proper orientation and migration directionality of late-generated cortical neurons.

\section{REELIN ACTS ON BOTH NEURONS AND RADIAL GLIAL CELLS}

During early stages of corticogenesis, newborn neurons find their way through the yet thin cortical wall. They only have to migrate from the ventricular zone (VZ)/SVZ to the deep cortical layers. As already pointed out, late-generated cortical neurons destined to superficial layers have to migrate for longer distances. This holds particularly true since the cortical plate (CP) and the intermediate zone (IZ) have become thicker at later developmental stages due to the continuous arrival of numerous neurons and the development of their dendritic and axonal processes. In order to traverse these larger distances successfully, late-generated neurons migrate along radial glial fibers, which span out between the ventricle and the pial surface, serving as a guiding scaffold for migrating cells (Rakic, 1972). Is Reelin involved in the correct orientation and targeting of radial glial fibers?

In a previous study, we were able to show that glial fibrillary acidic protein (GFAP)-positive processes of radial glial cells studied in a stripe choice assay with Reelin-containing stripes next to control stripes, started to branch as soon as they reached the Reelin stripes (Förster et al., 2002), suggesting that Reelin induces the branching of radial glial processes. Remarkably, when studying GFP-labeled radial glial fibers in vivo, they were found to branch as soon as they reached the Reelin-containing MZ (Chai et al., 2015). Next, we studied radial glial fibers in reeler mutant tissue and found that the number of branches arising from the main radial process was significantly reduced in reeler when compared to wild-type radial glial fibers (Chai et al., 2015). We concluded that Reelin induces the branching of radial glial fibers arriving at the MZ, thereby anchoring them to the cortical surface and allowing for the detachment of migrating neurons, which then finalize the migratory process by terminal translocation of the nucleus in the absence of a guiding radial fiber. Remarkably, branching of processes is associated with increased reorganization of the cytoskeleton, and future studies need to find out how Reelin in the MZ induces both branching and stabilization of the actin cytoskeleton by cofilin phosphorylation.

Since radial glial cells are precursors of neurons, we hypothesized that also the leading processes of neurons would start to branch upon arrival at the MZ. Indeed, the leading processes gave rise to branches precisely upon arrival at the Reelin-containing MZ (Figure 2). In the mature animal these branches in layer I represent the apical tuft of cortical pyramidal cells. When studying branching of the leading processes by real-time microscopy, we noticed that migration by nuclear translocation was terminated as soon as the large nucleus arrived at the thin branches of the main shaft of the leading process, suggesting that mechanical obstruction might play a role in the migratory arrest of late-generated neurons (Chai et al., 2015; O'Dell et al., 2015). As a result, the MZ containing the thin 
branches of the leading processes is almost free of cell bodies. Accordingly, the stop signal function of Reelin would be twofold: first, Reelin induces branching of the leading processes that cannot be entered by the translocating nucleus. Second, binding of Reelin to VLDLR receptors terminates migratory activity in wild-type neurons, but not in reeler neurons and in neurons deficient in VLDLR. Accordingly, many neurons in VLDLR knockout mice show "overmigration" into the MZ (Hack et al., 2007). In reeler mutants, Reelin-induced branching of radial glial fibers and of the leading processes of neurons is absent and neurons are not anchored to the $\mathrm{MZ}$ by these branches of the leading process. As a consequence, the leading processes do not remain attached to the cortical surface and point to various directions, often toward the VZ. We accordingly observed many neurons in reeler that did not migrate toward the cortical surface but in opposite direction toward the VZ. Similar observations were occasionally made in neurons transfected by IUE with the non-phosphorylatable form of cofilin ( $\operatorname{cofilin}^{\mathrm{S} 3 \mathrm{~A}}$ ) and more often in embryos transfected with cofilin $^{\mathrm{S} 3 \mathrm{E}}$. These findings in particular underscore the significant role of Reelin-induced cofilin phosphorylation for the orientation of the leading process and directed migration of cortical neurons. Indeed, we have previously shown that the phosphorylated form of cofilin is much enriched in and near the MZ (Chai et al., 2009). It is remarkable to note in this context that transfection of reeler embryos with pseudophosphorylated cofilin $^{\mathrm{S} 3 \mathrm{E}}$ or LIMK1 partially rescued orientation of the leading processes and the migration defect in reeler. In order to study the migratory behavior of the living cells in some detail, IUE with the various constructs was performed on E 14.5 and slice cultures of neocortex were prepared 3 days later, when many neurons destined to superficial layers were migrating (Figure 3). Together, these findings indicate that Reelin plays an important role in the proper orientation and stabilization of the leading process, allowing for directed migration towards the cortical

\section{REFERENCES}

Arber, S., Barbayannis, F. A., Hanser, H., Schneider, C., Stanyon, C. A., Bernard, O., et al. (1998). Regulation of actin dynamics through phosphorylation of cofilin by LIM-kinase. Nature 393, 805-809. doi: $10.1038 / 31729$

Bellenchi, G. C., Gurniak, C. B., Perlas, E., Middei, S., Ammassari-Teule, M., and Witke, W. (2007). N-cofilin is associated with neuronal migration disorders and cell cycle control in the cerebral cortex. Genes Dev. 21, 2347-2357. doi: $10.1101 /$ gad. 434307

Benhayon, D., Magdaleno, S., and Curran, T. (2003). Binding of purified Reelin to ApoER2 and VLDLR mediates tyrosine phosphorylation of disabled-1. Mol. Brain Res. 112, 33-45. doi: 10.1016/s0169-328x(03) 00032-9

Berry, M., and Rogers, A. W. (1965). The migration of neuroblasts in the developing cerebral cortex. J. Anat. 991, 691-709.

Chai, X., and Frotscher, M. (2016). How does Reelin signaling regulate the neuronal cytoskeleton during migration? Neurogenesis 3:e1242455. doi: 10.1080/23262133.2016.1242455

Chai, X., Förster, E., Zhao, S., Bock, H. H., and Frotscher, M. (2009). Reelin stabilizes the actin cytoskeleton of neuronal processes by inducing $n$-cofilin phosphorylation at serine3. J. Neurosci. 29, 288-299. doi: 10.1523/JNEUROSCI. 2934-08.2009 surface. Moreover, proper orientation of the leading process and its attachment to the MZ provides the tension required for nuclear translocation and the successful bypassing of early generated deep-layer neurons.

We were impressed to find such significant migration defects when transfecting wild-type embryos with cofilin $^{\mathrm{S} 3 \mathrm{~A}}$ and $\operatorname{cofilin}^{\mathrm{S} 3 \mathrm{E}}$ and to observe partial rescue of the reeler phenotype following transfection with LIMK1-although many other molecular players such as molecules of the tubulin cytoskeleton (e.g., Meseke et al., 2013; Förster, 2014), proneural transcription factors such as Rnd proteins (Pacary et al., 2011), and CLASP2 (Dillon et al., 2017) are also known to control the cytoskeleton of neuronal cells and extension and orientation of the leading process, migration by nuclear translocation associated with a myosin II-dependent flow of actin filaments (He et al., 2010), and eventually layer formation in the cerebral cortex.

\section{AUTHOR CONTRIBUTIONS}

MF developed the concept of this review article and wrote the manuscript. SZ, SW and XC performed the majority of the experiments reviewed in this article and contributed to manuscript writing and editing.

\section{ACKNOWLEDGMENTS}

The authors wish to thank the members of the Zhao lab and Frotscher lab for many stimulating discussions. The studies summarized in this review article were supported by grants from the Deutsche Forschungsgemeinschaft (FR 620/12-2, FR 620/13-1 and FR 620/14-1 to MF) and the National Natural Science Foundation of China (No. 31572477 to SZ). MF is Research Professor for Neuroscience of the Hertie Foundation.

Chai, X., Fan, L., Shao, H., Lu, X., Zhang, W., Li, J., et al. (2015). Reelin induces branching of neurons and radial glial cells during corticogenesis. Cereb. Cortex 25, 3640-3653. doi: 10.1093/cercor/bhu216

Chai, X., Zhao, S., Fan, L., Zhang, W., Lu, X., Shao, H., et al. (2016). Reelin and cofilin cooperate during the migration of cortical neurons: a quantitative morphological analysis. Development 143, 1029-1040. doi: 10.1242/dev. 134163

Cooper, J. A. (2008). A mechanism for inside-out lamination in the neocortex. Trends Neurosci. 31, 113-119. doi: 10.1016/j.tins.2007. 12.003

Cooper, J. A. (2013). Cell biology in neuroscience: mechanisms of cell migration in the nervous system. J. Cell Biol. 202, 725-734. doi: 10.1083/jcb.201305021

Curran, T., and D'Arcangelo, G. (1998). Role of reelin in the control of brain development. Brain Res. Rev. 26, 285-294. doi: 10.1016/s0165-0173(97)00035-0

D’Arcangelo, G., Miao, G. G., Chen, S. C., Soares, H. D., Morgan, J. I., and Curran, T. (1995). A protein related to extracellular matrix proteins deleted in the mouse mutant reeler. Nature 374, 719-723. doi: 10.1038/374719a0

D’Arcangelo, G., Homayouni, R., Keshvara, L., Rice, D. S., Sheldon, M., and Curran, T. (1999). Reelin is a ligand for lipoprotein receptors. Neuron 24, 471-479. doi: 10.1016/s0896-6273(00)80860-0

Dillon, G. M., Tyler, W. A., Omuro, K. C., Kambouris, J., Tyminski, C., Henry, S., et al. (2017). CLASP2 links Reelin to the cytoskeleton during neocortical development. Neuron 93, 1344.e5-1358.e5. doi: 10.1016/j.neuron.2017.02.039 
Dulabon, L., Olson, E. C., Taglienti, M. G., Eisenhuth, S., McGrath, B., Walsh, C. A., et al. (2000). Reelin binds alpha3betal integrin and inhibits neuronal migration. Neuron 27, 33-44. doi: 10.1016/s0896-6273(00)00007-6

Falconer, D. S. (1951). Two new mutants, "trembler" and "reeler", with neurological actions in the house mouse (Mus musculus L.). J. Genet. 50, $192-201$.

Förster, E. (2014). Reelin, neuronal polarity and process orientation of cortical neurons. Neuroscience 269, 102-111. doi: 10.1016/j.neuroscience.2014.03.004

Förster, E., Tielsch, A., Saum, B., Weiss, K. H., Johanssen, C., Graus-Porta, D., et al. (2002). Reelin, disabled 1 and betal integrins are required for the formation of the radial glial scaffold in the hippocampus. Proc. Natl. Acad. Sci. U S A 99, 13178-13183. doi: 10.1073/pnas.202035899

Förster, E., Zhao, S., and Frotscher, M. (2006a). Laminating the hippocampus. Nat. Rev. Neurosci. 7, 259-267. doi: 10.1038/nrn1882

Förster, E., Jossin, Y., Zhao, S., Chai, X., Frotscher, M., and Goffinet, A. M. (2006b). Recent progress in understanding the role of Reelin in radial neuronal migration, with specific emphasis on the dentate gyrus. Eur. J. Neurosci. 23, 901-909. doi: 10.1111/j.1460-9568.2006.04612.x

Frotscher, M. (1998). Cajal-Retzius cells, Reelin, and the formation of layers. Curr. Opin. Neurobiol. 8, 570-575. doi: 10.1016/s0959-4388(98) 80082-2

Frotscher, M. (2010). Role for Reelin in stabilizing cortical architecture. Trends Neurosci. 33, 407-414. doi: 10.1016/j.tins.2010.06.001

Golgi, C. (1873). Sulla struttura della sostanza grigia della cervello. Gazz. Med. Ital. Lombardia 6, 244-246.

Hack, I., Hellwig, S., Junghans, D., Brunne, B., Bock, H. H., Zhao, S., et al. (2007). Divergent roles of ApoER2 and Vldlr in the migration of cortical neurons. Development 134, 3883-3891. doi: 10.1242/dev.005447

He, M., Zhang, Z. H., Guan, C. B., Xia, D., and Yuan, X. B. (2010). Leading tip drives soma translocation via forward $\mathrm{F}$-actin flow during neuronal migration. J. Neurosci. 30, 10885-10898. doi: 10.1523/JNEUROSCI.0240-10.2010

Hiesberger, T., Trommsdorff, M., Howell, B. W., Goffinet, A., Mumby, M. C., Cooper, J. A., et al. (1999). Direct binding of Reelin to VLDL receptor and ApoE receptor 2 induces tyrosine phosphorylation of disabled-1 and modulates tau phosphorylation. Neuron 24, 481-489. doi: 10.1016/s0896-6273(00)80861-2

Hirota, Y., Kubo, K. I., Katayama, K. I., Honda, T., Fujino, T., Yamamoto, T. T., et al. (2014). Reelin receptors ApoER2 and VLDLR are expressed in distinct spatio-temporal patterns in developing mouse cerebral cortex. J. Comp. Neurol. 523, 463-478. doi: 10.1002/cne.23691

Howell, B. W., Herrick, T. M., and Cooper, J. A. (1999). Reelin-induced tyrosine phosphorylation of disabled 1 during neuronal positioning. Genes Dev. 13, 643-648. doi: 10.1101/gad.13.6.643

Ignatova, N., Sindic, C. J., and Goffinet, A. M. (2004). Characterization of the various forms of the Reelin protein in the cerebrospinal fluid of normal subjects and in neurological diseases. Neurobiol. Dis. 15, 326-330. doi: 10.1016/j.nbd. 2003.11.008

Jossin, Y., Bar, I., Ignatova, N., Tissir, F., De Rouvroit, C. L., and Goffinet, A. M. (2003). The reelin signaling pathway: some recent developments. Cereb. Cortex 13, 627-633. doi: 10.1093/cercor/13.6.627

Lambert de Rouvroit, C., de Bergeyck, V., Cortvrindt, C., Bar, I., Eeckhout, Y., and Goffinet, A. M. (1999). Reelin, the extracellular matrix protein deficient in reeler mutant mice, is processed by a metalloproteinase. Exp. Neurol. 156, 214-217. doi: 10.1006/exnr.1998.7007

Meseke, M., Cavus, E., and Förster, E. (2013). Reelin promotes microtubule dynamics in processes of developing neurons. Histochem. Cell Biol. 139, 283-297. doi: 10.1007/s00418-012-1025-1

Nadarajah, B., and Parnavelas, J. G. (2002). Modes of neuronal migration in the developing cerebral cortex. Nat. Rev. Neurosci. 3, 423-432. doi: 10.1038/ nrn845
Nadarajah, B., Brunstrom, J. E., Grutzendler, J., Wong, R. O., and Pearlman, A. L. (2001). Two modes of radial migration in early development of the cerebral cortex. Nat. Neurosci. 4, 143-150. doi: 10.1038/83967

Nichols, A. J., and Olson, E. C. (2010). Reelin promotes neuronal orientation and dendritogenesis during preplate splitting. Cereb. Cortex 20, 2213-2223. doi: 10.1093/cercor/bhp303

O’Dell, R. S., Cameron, D. A., Zipfel, W. R., and Olson, E. C. (2015). Reelin prevents apical neurite retraction during terminal translocation and dendrite initiation. J. Neurosci. 35, 10659-10674. doi: 10.1523/JNEUROSCI.162915.2015

Ogawa, M., Miyata, T., Nakajima, K., Yagyu, K., Seike, M., Ikenaka, K., et al. (1995). The reeler gene-associated antigen on Cajal-Retzius neurons is a crucial molecule for laminar organization of cortical neurons. Neuron 14, 899-912. doi: 10.1016/0896-6273(95)90329-1

Pacary, E., Heng, J., Azzarelli, R., Riou, P., Castro, D., Lebel-Potter, M., et al. (2011). Proneural transcription factors regulate different steps of cortical neuron migration through Rnd-mediated inhibition of RhoA signaling. Neuron 69, 1069-1084. doi: 10.1016/j.neuron.2011.02.018

Rakic, P. (1972). Mode of cell migration to the superficial layers of fetal monkey neocortex. J. Comp. Neurol. 145, 61-83. doi: 10.1002/cne.9014 50105

Rakic, P., and Caviness, V. S. (1995). Cortical development: view from neurological mutants two decades later. Neuron 14, 1101-1104. doi: 10.1016/08966273(95)90258-9

Ramón y Cajal, S. R. (1911). Histologie du système nerveux de l'homme et des vertébrés. Paris: Maloine.

Senzaki, K., Ogawa, M., and Yagi, T. (1999). Proteins of the CNR family are multiple receptors for Reelin. Cell 99, 635-647. doi: 10.1016/s00928674(00)81552-4

Sheldon, M., Rice, D. S., D’Arcangelo, G., Yoneshima, H., Nakajima, K., Mikoshiba, K., et al. (1997). Scrambler and yotari disrupt the disabled gene and produce a reeler-like phenotype in mice. Nature 389, 730-733. doi: $10.1038 / 39601$

Tissir, F., and Goffinet, A. M. (2003). Reelin and brain development. Nat. Rev. Neurosci. 4, 496-505. doi: 10.1038/nrn1113

Trommsdorff, M., Gotthardt, M., Hiesberger, T., Shelton, J., Stockinger, W., Nimpf, J., et al. (1999). Reeler/disabled-like disruption of neuronal migration in knockout mice lacking the VLDL receptor and ApoE receptor 2. Cell 97, 689-701. doi: 10.1016/s0092-8674(00)80782-5

Yang, N., Higuchi, O., Ohashi, K., Nagata, K., Wada, A., Kangawa, K., et al. (1998). Cofilin phosphorylation by LIM-kinase 1 and its role in rac-mediated actin reorganization. Nature 393, 809-812. doi: 10.1038/31735

Zhao, S., and Frotscher, M. (2010). Go or stop? Divergent roles of Reelin in radial neuronal migration. Neuroscientist 16, 421-434. doi: $10.1177 / 1073858410367521$

Zhao, S., Chai, X., Förster, E., and Frotscher, M. (2004). Reelin is a positional signal for the lamination of dentate granule cells. Development 131, 5117-5125. doi: $10.1242 /$ dev.01387

Conflict of Interest Statement: The authors declare that the research was conducted in the absence of any commercial or financial relationships that could be construed as a potential conflict of interest.

Copyright (c) 2017 Frotscher, Zhao, Wang and Chai. This is an open-access article distributed under the terms of the Creative Commons Attribution License (CC BY). The use, distribution or reproduction in other forums is permitted, provided the original author(s) or licensor are credited and that the original publication in this journal is cited, in accordance with accepted academic practice. No use, distribution or reproduction is permitted which does not comply with these terms. 